\title{
In vitro fertilization of mouse oocyte
}

Agathe Chaigne

MRC Laboratory for Molecular Cell Biology, University College London, London, United Kingdom. a.chaigne@ucl.ac.uk

\section{Summary/abstract}

The early development of embryos is a widely studied process. Fertilization is the consequence of the fusion of two haploid gametes, the oocyte and the sperm. In mammals, such as human and mouse, this occurs in the female genital tracks. However, imaging in utero is still very limited, which prompts the use of extra utero techniques. In particular, in vitro fertilization provides a quick and simple way to study the very early steps of mouse embryo development. Here, I describe a simple and hands-on protocol to perform in vitro fertilization using the mouse as a model system.

\section{Key words (5-10)}

Mouse oocyte, superovulation, in vitro fertilization, zygote.

\section{Running head: In vitro fertilization}

\section{Introduction}

The development of the mammalian early embryo is vastly studied, in particular because it has tremendous implications in human fertility treatments. Yet a lot remains unknown about early embryogenesis in mammals. For example, while in other species the axis of the embryo is specified early on even before fertilization, early mammal development is highly regulative (1). In mammals, the stage where the embryo axis is determined and the amount of plasticity (2-4) are thus still controversial.

In the mouse, while it is possible to study the development of the early embryo by mating, sacrifice of the female and subsequent collection of fertilized embryos, it can be necessary to perform in vitro fertilization in order to access the very early steps of mouse embryo development. This technique permits to follow gametes fusion, termination of meiosis (second anaphase followed by the extrusion of the second 
polar body), gathering of the two pronuclei (from the oocyte and sperm) and first mitotic division of the embryo, also called zygote $(5,6)$. Furthermore, in vitro fertilization allows for a better time resolution when following those events because the timing of fertilization is known with an hour precision. Here I describe a step-bystep simple but efficient protocol to perform in vitro fertilization (thereafter referred to as IVF) in mice. This protocol requires performing optional follicle stimulation on day 1 , superovulation of female mice on day 3 , sacrifice of the male and female mice and fertilization of the metaphase II ovulated oocytes on day 4.

\section{Materials}

2.1 Mice: 5-8 weeks old female mice, 11 weeks old male mice.

2.2 Fertilization medium (7) $357 \mathrm{mg} \mathrm{NaCl}, 105 \mathrm{mg} \mathrm{NaHCO}, 5.3 \mathrm{mg} \mathrm{KCl}, 2.8 \mathrm{mg}$ $\mathrm{NaH}_{2} \mathrm{PO}_{4}, 50 \mathrm{mg}$ Glucose, 17. $35 \mathrm{mg} \mathrm{CaCl} 22 \mathrm{H}_{2} 0,10.25 \mathrm{MgCl}_{2} 6 \mathrm{H}_{2} 0,3 \mathrm{mg}$ Penicillin in Braun water. For $50 \mathrm{~mL}$ make a $10 \mathrm{X}$ concentrate with $\mathrm{NaCl}, \mathrm{NaHCO}_{3}, \mathrm{KCl}$, $\mathrm{NaH}_{2} \mathrm{PO}_{4}$, Glucose. The reason for making a $10 \mathrm{X}$ solution is simply to avoid weighing very small quantities and making measurement mistakes, in particular with $\mathrm{CaCl}_{2}, 2 \mathrm{H}_{2} \mathrm{O}$ and $\mathrm{MgCl}_{2}, 6 \mathrm{H}_{2} \mathrm{O}$ that are both hydrated and thus tend to agglomerate. Dilute in $20 \mathrm{~mL} \mathrm{H} \mathrm{H}_{2} \mathrm{O}$ Braun. Agitate for a few minutes. Add $\mathrm{CaCl}_{2}, 2 \mathrm{H}_{2} \mathrm{O}$ and $\mathrm{MgCl}_{2}$, $6 \mathrm{H}_{2} \mathrm{O}$ at $10 \mathrm{X}$. Agitate for a few minutes. Add water to $50 \mathrm{~mL}$ final. Dilute to $1 \mathrm{X}$ in Braun water and add penicillin to final concentration of $60 \mu \mathrm{g} / \mathrm{mL}$. Filtrate. Prepare aliquots and keep at $4^{\circ} \mathrm{C}$ no more than 1 week. The day before the experiment, add BSA to a final concentration of $5 \mathrm{mg} / \mathrm{mL}$ (see Note 1). Put a small drop (0.3-0.5 mL) of this complete fertilization medium under mineral oil (see Note 2) to equilibrate in a $5 \% \mathrm{CO}_{2}$ incubator at least an hour before the experiment, or overnight.

2.3 Culture medium (M2), prepare the following stock solutions.

- Stock solution A (10X): $\mathrm{NaCl} 5.534 \mathrm{~g}, \mathrm{KCl} 0.360$ g, $\mathrm{KH}_{2} \mathrm{PO}_{4} 0.162 \mathrm{~g}, \mathrm{MgSO}_{4} 7 \mathrm{H}_{2} \mathrm{O}$ $0.294 \mathrm{~g}$, sodium lactate syrup (60\% volume syrup) $4.347 \mathrm{~g}$, D-glucose $1 \mathrm{~g}$, Penicillin $1000 \mathrm{U} / \mathrm{mL}$, Streptomycin $0.5 \mathrm{~g} / \mathrm{mL}$, Braun water up to $100 \mathrm{~mL}$. Filtrate. This solution can be kept for 3 months at $4^{\circ} \mathrm{C}$. 
- Stock solution B (10X): $\mathrm{NaHCO}_{3} 2.106 \mathrm{~g}$, Braun water up to $100 \mathrm{~mL}$. This solution can be kept for 2 weeks at $4^{\circ} \mathrm{C}$.

- Stock solution C (100X): sodium pyruvate $0.036 \mathrm{~g}$, Braun water up to $10 \mathrm{~mL}$. This solution can be kept for 2 weeks at $4^{\circ} \mathrm{C}$.

- Stock solution D (100X): $\mathrm{CaCl}_{2} 2 \mathrm{H}_{2} 00.252 \mathrm{~g}$, Braun water up to $10 \mathrm{~mL}$. Filtrate. This solution can be kept for 2 weeks at $4^{\circ} \mathrm{C}$.

- Stock solution E (100X): Hepes $5.957 \mathrm{~g}$, Braun water up to $100 \mathrm{~mL}$ after adjusting the $\mathrm{pH}$ to 7.4 with $\mathrm{NaOH}$. Filtrate. This solution can be kept for 3 months at $4^{\circ} \mathrm{C}$.

To prepare the medium, mix $1 \mathrm{~mL}$ of solution $\mathrm{A}, 0.16 \mathrm{~mL}$ of solution $\mathrm{B}, 0.1 \mathrm{~mL}$ of solution C, $0.1 \mathrm{~mL}$ of solution $\mathrm{D}, 0.84 \mathrm{~mL}$ of solution E, $40 \mathrm{mg}$ of BSA (see Note 1) and $7.8 \mathrm{~mL}$ of Braun water. Adjust the $\mathrm{pH}$ to 7.4 with $\mathrm{NaOH}$ before adding the total volume of Braun water and filtrate. Prepare single use aliquots $(4 \mathrm{~mL})$.

2.3 PMS (Pregnant Mare Serum, Chronogest) diluted in $\mathrm{NaCl} 0.9 \%$ filtrated to a final concentration $50 \mathrm{IU} / \mathrm{mL}$. Make aliquots and store at $-20^{\circ} \mathrm{C}$. Thaw before use and keep solution at $4^{\circ} \mathrm{C}$ for 1 week maximum.

2.4 HCG (Human Chorionic Gonadotropin, Chronogest) diluted in $\mathrm{NaCl} 0.9 \%$ filtrated to a final concentration $50 \mathrm{IU} / \mathrm{mL}$. Make aliquots and store at $-20^{\circ} \mathrm{C}$. Thaw before use and keep solution at $4{ }^{\circ} \mathrm{C}$ for 1 week maximum.

\section{Methods}

\subsection{Day 1: injection of females with PMS (optional)}

This step increases the number of mature follicles available for IVF. To obtain around 50 embryos, 2 to 4 females must be used.

During the day (see Note 3 ), allow the hormone to equilibrate at room temperature. Inject $0.1 \mathrm{~mL}$ PMS with an insulin syringe $(0.3 \mathrm{~mL})$ in the abdomen of the mouse, making sure not to inject bubbles. Massage the mouse where injected. 


\subsection{Day 3: Superovulation and media preparation}

\subsubsection{Injection of females with HCG}

This step induces ovulation.

During the day, $48 \mathrm{~h}$ after PMS injection (see Note 3), allow hormone to equilibrate at room temperature. Inject $0.1 \mathrm{~mL} \mathrm{HCG}$ with an insulin syringe $(0.3 \mathrm{~mL})$ in the abdomen of the mouse, making sure not to inject bubbles. Massage the mouse where injected.

\subsubsection{Media preparation}

Prepare the fertilization medium and the culture medium M2.

Add BSA to a final concentration of $5 \mathrm{mg} / \mathrm{mL}$ to the fertilization medium (see Note 1) and put a drop ( 0.3 to $0.5 \mathrm{~mL})$ of this complete fertilization medium in a culture dish under mineral oil to equilibrate in a $5 \% \mathrm{CO}_{2}$ incubator at $37^{\circ} \mathrm{C}$ overnight. Prepare one culture dish per male and one culture dish per three female mice used for IVF (for four female mice and more prepare two dishes).

\subsection{Day 4: IVF}

\subsubsection{Sperm preparation}

12 to $14 \mathrm{~h}$ after HCG injection, kill the male mice by cervical dislocation. Tear the abdomen skin and open the abdomen to reveal the testicles. Remove the two Cauda epididymis with a piece of Corpus epididymis and a piece of Vas deferens (Figure 1) and place them in the drop of equilibrated complete fertilization medium under oil. Use one dish per male.

Squeeze to allow the sperm to be released by the Vas deferens like toothpaste. If it does not work, puncture the epididymis with a needle and squeeze. Remove the rest of the epididymis from the drop. Gently shake the dish to spread the sperm (do not pipette up and down). Remove the big aggregates that stick to the bottom of the dish (see Note 4). Incubate this sperm solution for 1.5 to $2 \mathrm{~h}$ in $5 \% \mathrm{CO}_{2}$ at $37^{\circ} \mathrm{C}$ to enable capacitation.

\subsubsection{Cumulus isolation and IVF}


A few minutes before capacitation is over (i.e. 14 to $16 \mathrm{~h}$ after HCG injection), kill the female mice by cervical dislocation. Tear the abdomen skin and open the abdomen. Isolate the oviducts from the superovulated females (Figure 2). Place the oviducts in the mineral oil next to the drop of equilibrated complete fertilization medium. Use one dish for three females. Hold the oviduct with a clamp and pierce the ampulla with a needle. Drag the cumulus containing the oocytes with the needle from the mineral oil inside the drop (Figure 2). Repeat for the other oviducts.

Add 8 to $12 \mu \mathrm{L}$ of the sperm solution to the drop containing the cumulus. Incubate for 2 to $4 \mathrm{~h}$. A longer incubation will lead to better IVF efficiency, but a shorter time will lead to a more synchronized embryo population.

Prepare a dish with several drops of culture medium M2 under mineral oil. Remove the fertilized embryos from the equilibrated complete fertilization medium. Wash them in a few drops of M2. Fertilized eggs should display a fertilization cone. The two polar bodies are not necessarily visible at that stage because they can degenerate rapidly.

\subsubsection{Timings and further procedures}

Wait at least 30 minutes before performing any further procedure. The embryos should then display at least one or the two pronuclei. Microinjection of cRNA (8) or other procedures are then possible.

The two pronuclei will migrate towards the zygote center in 12 to $15 \mathrm{~h}$ and the first division should take place in OF1 mice around 15 to $20 \mathrm{~h}$ post transfer into M2 (6). The precise timing is strain dependent.

\section{Notes}

- Note 1: The quality of the BSA used in the fertilization medium is critical. The BSA should be kept at $4^{\circ} \mathrm{C}$. Some batches work better than others.

- Note 2: As for oocyte maturation, the quality of the mineral oil is critical. It should be kept in the dark. Some batches work better than others.

- Note 3: It is important to be consistent with the time of injection of the hormones. They should be injected around the same time $48 \mathrm{~h}$ apart. The hormones can be injected any time during the day, preferentially in the end of the afternoon, but not 
during the night; night follicle stimulation and superovulation can interfere with the mice natural cycles and lead to relatively inefficient ovulation. PMS can sometimes be skipped if the females already produce a reasonable amount of good quality oocytes arrested in metaphase II. The IVF per se should be performed 14 to $16 \mathrm{~h}$ after HCG injection.

- Note 4: Sperm aggregates correlate with embryos sticking to the bottom of the dish. In that case, they often do not go through the first embryonic division.

\section{References}

1. A. Martinez Arias, J. Nichols, and C. Schröter (2013) A molecular basis for developmental plasticity in early mammalian embryos, Development (Cambridge, England). 140, 3499-3510.

2. T. Hiiragi and D. Solter (2004) First cleavage plane of the mouse egg is not predetermined but defined by the topology of the two apposing pronuclei, Nature. 430, 360-364.

3. B. Plusa, K. Piotrowska, and M. Zernicka-Goetz (2002) Sperm entry position provides a surface marker for the first cleavage plane of the mouse zygote, Genesis (New York, N.Y.: 2000). 32, 193-198.

4. M.H. Johnson (2009) From Mouse Egg to Mouse Embryo: Polarities, Axes, and Tissues, Annual Review of Cell and Developmental Biology. 25, 483-512.

5. B. Maro, M.H. Johnson, S.J. Pickering, et al. (1984) Changes in actin distribution during fertilization of the mouse egg, Journal of Embryology and Experimental Morphology. 81, 211-237.

6. A. Chaigne, C. Campillo, R. Voituriez, et al. (2016) F-actin mechanics control spindle centring in the mouse zygote, Nature Communications. 7, 10253.

7. A. Ajduk, M.A. Ciemerych, V. Nixon, et al. (2008) Fertilization differently affects the levels of cyclin B1 and M-phase promoting factor activity in maturing and metaphase II mouse oocytes, Reproduction (Cambridge, England). 136, 741752.

8. M.-H. Verlhac (2000) Mos activates MAP kinase in mouse oocytes through two opposite pathways, The EMBO Journal. 19, 6065-6074.

\section{Figure Captions}

Figure 1: Schematics of the male mouse reproductive ducts. In red are the parts that should be isolated for in vitro fertilization.

Figure 2: Schematics of the female mouse reproductive ducts. In red are the parts that should be isolated for in vitro fertilization. 


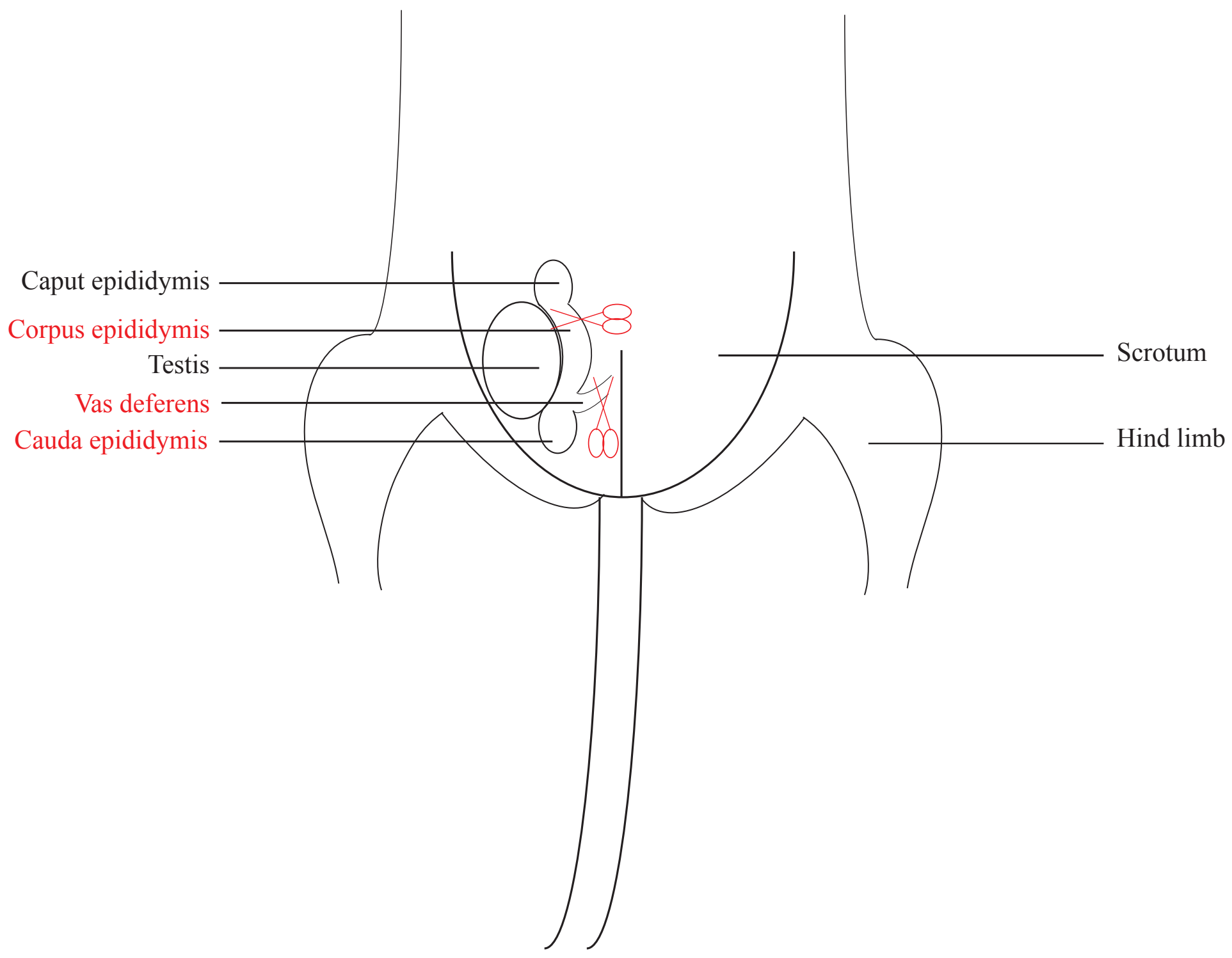

Figure 1 


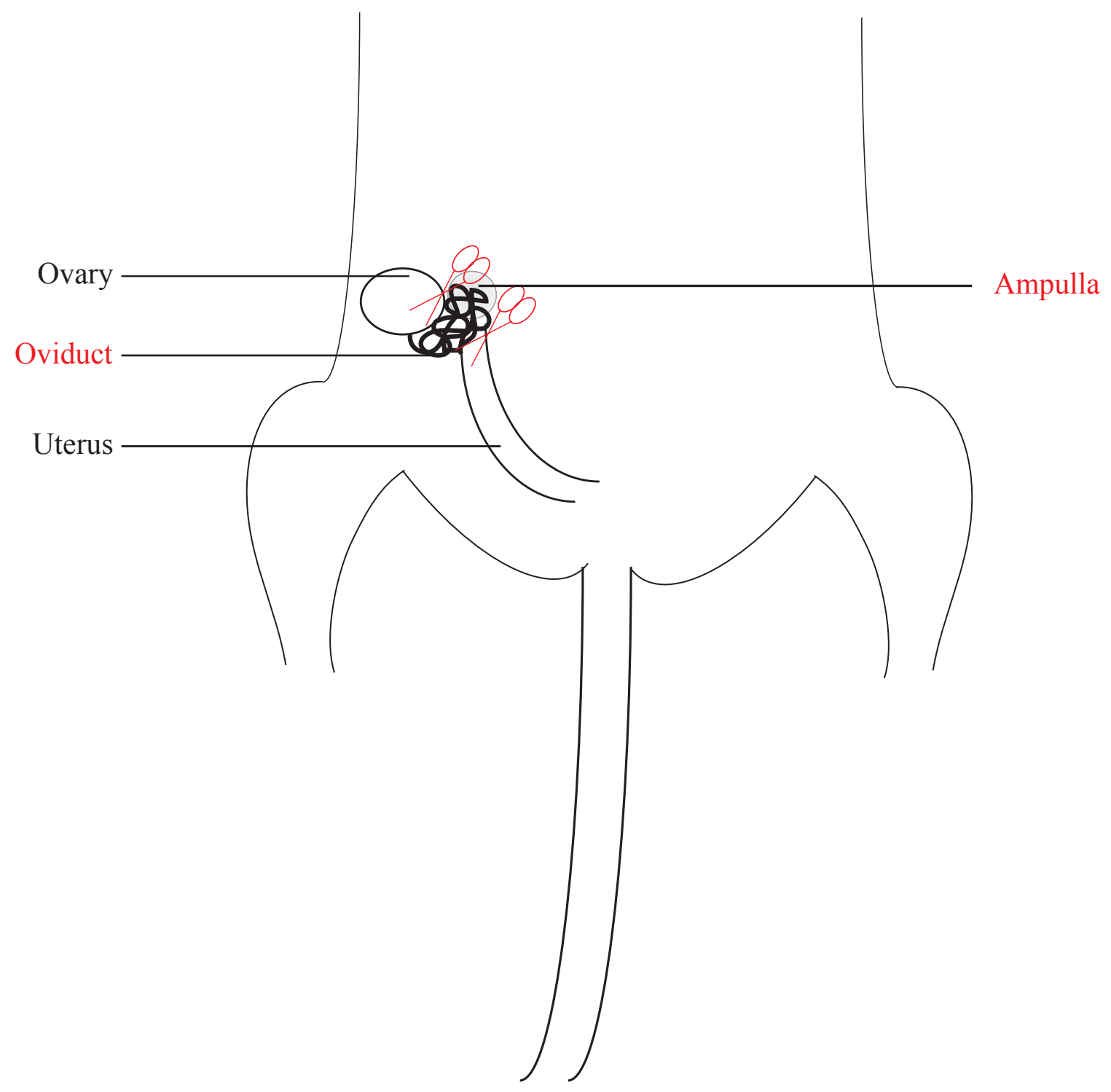

Figure 2 